\title{
Estimation of Production Function of Direct Health Care Services Delivered by Iranian Social Security Organization
}

\author{
Sattar Mehraban ${ }^{1 *}$, Hossein Raghfar ${ }^{1,2}$ \\ ${ }^{1}$ Research Center of Economic Studies, Alzahra University, Tehran, Iran. ${ }^{2}$ Department of Economics, Alzahra \\ University, Tehran, Iran.
}

\section{First Published online June 30, 2016}

\begin{abstract}
Background and Objectives: Social Security Organization (SSO) is the second largest organization to the Ministry of Health and Medical Education (MOHME) in providing health care services in Iran. In recent years the gap between the SSO's resources and expenditures has shown an unprecedented growing trend due to the rapidly increasing demand. Continuation of this trend may lead to financial imbalance in the following years, which would negatively impact access of public to health care services. This study, thus, seeks to explore factors affecting the efficiency of SSO's health care services in quest for solutions to alleviate the potentially critical situation ahead.

Methods: A microeconomic analysis was carried out by panel stochastic frontier approach (SFA) method. CobbDouglas production function was estimated based on maximum likelihood estimation (MLE), using 7-year panel data derived from the yearbooks of SSO (2008-2015). The annual admission rate was selected as the output variable and it was assumed to be a function the number of physicians, nurses, active beds, paraclinical and other staff, and the bed restoration interval. Calculation was carried out using Frontier version 4.1 software.

Findings: Significant elasticity coefficient of $0.835,0.073,0.0273,-0.199$ was obtained for active beds, physicians, nurses, and bed restoration interval respectively. The marginal production of inputs was calculated to be 79.14, 9.48 , and 1.73 for active beds, physicians and nurses, respectively. The marginal rate of technical substitution (MRTS) was identified to be 0.18 for nurse-physician, 0.02 for nurse-bed, and 0.12 for physician-bed substitution. The $\eta$ and $\gamma$ were calculated to be 0.015 and 0.581 , respectively.

Conclusions: Our results clearly shows that the production (annual patient admission rate) in SSO's hospital is capital intensive being highly dependent on number of active beds with increasing return to scale. The inefficiency has only marginally decreased over time, yet there is room to improve production by increasing efficiency. The MRTS for nurse-physician substitution suggests that the escalating burden of physicians' wage may be reduced by employing nurses in the services they can deliver instead of physicians. The negative contribution of bed restoration interval to production highlights the challenging nature of quality improvement by increased average length of stay (ALS), which is currently low in SSO's hospitals. The problem of inconsistency between quality services and high production, thus, persist pointing to the need for in-depth reform in the structure of health care delivery.
\end{abstract}

Keyword: Hospital economics, Health care delivery, Financial management, Health Care System, Social security, Organizational efficiency

\section{Background and Objectives}

Almost all countries are faced with increasing health care costs due to demographic changes, evolving disease, and new technologies. ${ }^{1}$ The average cost of health care around the globe increased from $6.56 \%$ of gross domestic product (GDP) in 1995 to $7.75 \%$ in 2013 , and from US\$535 to US\$1247 per capita. ${ }^{2}$ Among the various components of health systems, hospitals are responsible for

${ }^{*}$ Corresponding Author: Sattar Mehraban, Research Center of Economic Studies, Alzahra University, Tehran, Iran. Tel: +98 9122182298, Fax: +98 1122334367, Email: h.raghfar@alzahra.ac.ir the majority of these expenditures. ${ }^{3,4}$ In developing countries hospital industry absorb $50 \%$ of national health budget ${ }^{5}$ and attract a large part of university-trained health workforce. ${ }^{6-8}$ In Iran, the share of GDP in health expenditures has increased from $3.8 \%$ in 1995 to $6.7 \%$ in 2013 , and hospitals now account for more than $42 \%$ of national health expenditure, $40 \%$ of doctors, and $80 \%$ of nurses. ${ }^{2,9}$

The Social Security Organization (SSO) is the second largest institution following the Ministry of Health and Medical Education (MOHME) responsible for providing healthcare services in Iran, covering more than $71 \%$ of 
the urban population. ${ }^{10}$ While the health expenditures have jumped as high as $52.8 \%$ from 2014 to 2015, the corresponding resources have increased only $17 \%$. This situation together with the accelerated pace of Iranian population aging is going to violate the balance between resources and demand in the SSO. ${ }^{11}$ Given the unique status of SSO in providing health care to the population, the above-mentioned situation requires immediate attention to keep SSO health care activities economically viable. ${ }^{10}$

Bed occupancy rate (BOR) and average length of stay (ALS) are key indicators of hospital performance. ${ }^{12-16}$ The average BOR of SSO hospitals is reported to be $76.1 \%,{ }^{11}$ close to that of OECD countries (77\%), Belgium (78\%) and France (75\%), higher than that of the United States $(65 \%$,) and lower than that of Norway and Canada (90\%) and the United Kingdom (85\%), as reported in 2013. ${ }^{13}$

On the other hands, the ALS in SSO hospitals is reported to be 2.7 days which is extremely lower than that of the OECD countries ( 8.1 days) ${ }^{11}$ and even below the minimum standard of 3.5 days required by the MOHME. ${ }^{17}$ This situation suggests that the relatively high BOR of SSO hospitals is achieved at the expense of compromised quality of health care represented by ALS.

While available data suggest that the SSO's health care organizations are already under extreme economic pressure to the extends that the quality of care is obviously scarified in the favor of reduced costs, the increasing gap between growth of expenditures and resources as revealed by recent statistics depict the possibility of financial crisis in these organizations in the upcoming years. The potentially critical situation ahead calls for application of scientific approaches to identify the current situation in detailed economic terms and seek for efficient solutions to rationalize the allocation of resources, improve quality of services, and attain higher efficiency. ${ }^{18,19}$ Multiple groups have previously explored the efficiency of SSO hospitals using various microeconomic approaches. ${ }^{20-24}$ These studies have shown that inefficiency of human resources can increase hospital costs due to the induced demand and total organizational costs. In addition, it has been revealed that the initial resources for health care delivery can be reduced without any negative effect on the hospital outputs. ${ }^{20-24}$ The useful insights obtained from these studies encourage further investigation of SSO hospitals' economy in quest to reach higher efficiency solutions. Thus, the present study was conducted to estimate the production function of direct health care services delivered by SSO hospitals and explore the contribution of input variables to an overall representative output, i.e. admission rate. Estimation of hospital production function would serve as a decision support tool to control costs, increase efficiency, and improve services quality.

\section{Methods}

Microeconometric Model

We used stochastic frontier approach (SFA) ${ }^{25-29}$ to estimate production function. SFA is a parametric technique with relatively low sensitivity to outliers and high capability to distinguish random error from inefficiency, making it more suitable for hospital-specific data as compared with non-parametric methods such as data envelopment analysis. ${ }^{30}$

\section{Model Selection}

SFA requires assumptions about the form of the production function and the distribution of the error terms. CobbDouglas and Transcendental functions are the 2 popular models frequently used to estimate hospital production. ${ }^{31}$ While the Cobb-Douglas function is easy to estimate, its main drawback is that it assumes constant input elasticities and technical substitution rates. Alternatively, the Transcendental production function, which is an extension of the Cobb-Douglas model, allows for variable production elasticity. ${ }^{32}$

F-test was used to select between Cobb-Douglas (restricted) and transcendental (non-restricted) functions. F-value was calculated to be 7.175 which is significantly higher than the tabular $\mathrm{F}$ value of 2.89 ( $d f=6196$ and $P=.01$ ). Thus, the restricted model (Cobb-Douglas function) was found to be more suitable to capture our data. A mathematical description of Cobb-Douglas production function is given in Additional File 1.

\section{The Data, Output, and Inputs}

Seven-year time series (2008-2015) were collected from the statistical yearbooks of SSO published in 2015. All Iranian provinces in which SSO owns medical centers were involved. Data were collected at provincial level and each province was considered as a single decision-making unit. The annual rate of patient admission was specified as the only output variables because of the limited information on other output indicators. Five input variables were incorporated into the model, including active beds (representing capital goods), the number of physicians, nurses, paraclinical staff, and personnel (representing the human resources), and the bed restoring interval (representing efficiency of bed utilization). Thus the output variable was assumed to follow the input variables as the following:

Annual admissions = $f$ (hospital beds, nurses, doctors, paraclinical staff, other staff, and the bed restoration interval)

The Cobb-Douglas production was estimated using 
maximum likelihood estimation (MLE). Calculation was carried out using Frontier version 4.1 software.

\section{Results}

Table 1 shows the results of Cobb-Douglas function estimated based on our data. Of the coefficients of 6 major variables included in the model, the absolute largest value is related to active beds, followed by bed restoration interval, and physicians. The smallest absolute coefficient is obtained for other staff, and the only minus coefficients is related to bed restoration interval and paraclinical staff. All model coefficients except for those of paraclinical staff and other staff are statistically significant.

\section{The Parameters and Efficiency Scores}

Figure 1 shows the average technical efficiency of direct healthcare services provided by SSO hospitals during 2008-2014. As seen, the technical efficiency shows an increasing trend over the recent 7-year period. Although the increase of efficiency is marginal and limited to total of $1.4 \%$ from 2008 to 2014 , the efficiency during this period is acceptable. Consistently, the coefficient $\eta$ was calculated to be 0.015 , indicating that inefficiency has decreased over time. The coefficient $\mathrm{y}$ was calculated to be 0.581 which indicates that the role of inefficiency is greater than that of random factors.

\section{The Return to Scale, Marginal Productivity and MRTS} The total input elasticity in 2-sided logarithmic model represents the status of return to the scale. The sum of inputs coefficients was calculated to be 1.1368 (>1), indicative of an increasing return to scale for direct healthcare services.

Table 2 presents the estimated marginal production. The by far highest marginal production input is represented by active beds, followed by physicians and nurses. Ac-
Table 1. Maximum Likelihood Estimates of the Cobb-Douglas Regression Coefficients

\begin{tabular}{lcc}
\hline Variable & Coefficient & SE \\
\hline Constant & $0.5814^{* * *}$ & 0.15478 \\
Log active bed & $0.8355^{* * *}$ & 0.0279 \\
Log physicians & $0.0730^{* *}$ & 0.0260 \\
Log nurses & $0.0287^{*}$ & 0.0167 \\
Log paraclinic staffs & -0.0247 & 0.0180 \\
Log other staffs & 0.0201 & 0.0152 \\
Log interval of restoring the beds & $-0.1996^{\star * *}$ & 0.0228 \\
Sigma-squared & $0.0257^{* *}$ & 0.0095 \\
Gamma & $0.58177^{* * *}$ & 0.0927 \\
Mu & $0.2446^{* * *}$ & 0.0700 \\
Eta & $0.0151^{*}$ & 0.0187 \\
\hline
\end{tabular}

Abbreviation: SE, Standard error.

${ }^{* * *}$ Significant at the 0.001 percent level. **Significant at the 0.01 percent level. ${ }^{*}$ Significant at the 0.05 percent level.

Table 2. Marginal Production of Active Beds, Physicians, and Nurses

\begin{tabular}{lll}
\hline Nurses & Physicians & Active Beds \\
\hline 1.73 & 9.48 & 79.14 \\
\hline
\end{tabular}

cording to our calculations, adding one active bed will yield in an increase of 79.14 in annual admissions. Moreover, addition of one unit of each of physician and nurse as an input will increase the patient admissions by 9.48 and 1.73 unite, respectively. The marginal production values indicate that the production in direct healthcare services of SSO is capital-intensive.

Table 3 shows the marginal rate of technical substitution (MRTS) of production factors. While the largest MRTS was related to nurse-physician ratio, the nurse-bed ratio represents the smallest value. The positive sign of the marginal rates of substitution between the three produc-

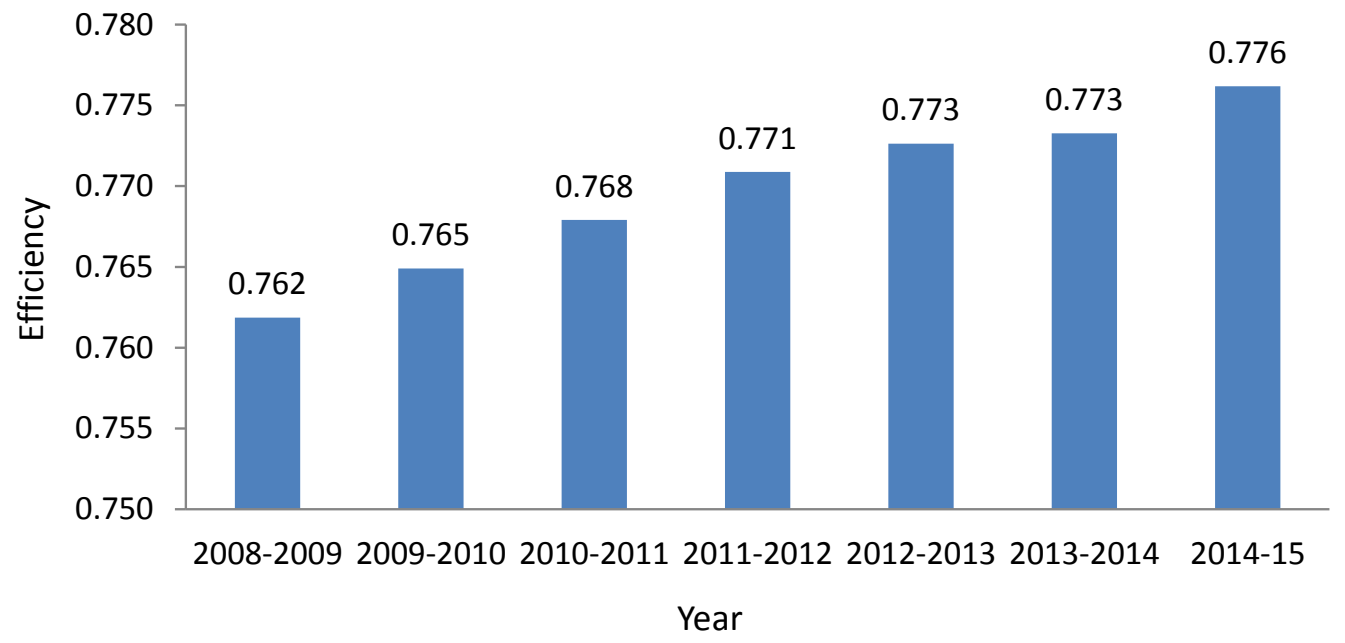

Figure 1. Mean Technical Efficiency of SSO's Hospitals During 2008-2015. 
Table 3. Marginal Rates of Technical Substitution between Active Beds, Physicians, and Nurses

\begin{tabular}{lll}
\hline MRTS $_{\mathrm{N}, \mathrm{P}}$ & Physicians $_{\mathrm{N}, \mathrm{B}}$ & Active Beds $_{\mathrm{P}, \mathrm{B}}$ \\
\hline 0.18 & 0.02 & 0.12 \\
\hline
\end{tabular}

tion factors, suggests that the factors have succeeded each other in the production process.

\section{Discussion}

This study was conducted to update the estimation of production function of SSO hospitals in terms of direct health care services. Our results predict that the increase of active beds by a factor of $10 \%$ would increase the hospital admissions up to $8.35 \%$ when all other factors remain constant. The positive effect of active beds on hospital admissions has been mentioned by several investigators. ${ }^{33-38}$ At the same time, the marginal product of active bed input showed that production in the direct healthcare services is capital-intensive. Therefore, inefficient use of active beds increases the ratio of cost to income in healthcare services, resulting in the financial imbalance. The annual cost of beds may reach up to be 1.5 times as much as the annual revenue in inefficient hospitals. ${ }^{39}$ In addition, since recruitment in the health sector should be based on the number of the beds, the unused bed capacity will also increase the costs of human resources. Based on the latest statistics (2014), the BOR of SSO hospitals is $76.1 \%{ }^{11}$ which shows the room for considerable improvement when compared with the corresponding rate in Norway and Canada (90\%) and the United Kingdom (85\%). ${ }^{13}$ The very high contribution of active beds in production of SSO hospitals, hence, encourages focused planning to achieve higher BOR as a potential strategy to narrow the increasing gap between the resources and the costs derived by the escalating demand.

Based on our results $10 \%$ increase in the number of physicians would increase hospital admissions by a factor of $0.73 \%$. This finding is consistent with the studies of Jensen and Morrisey, ${ }^{33}$ Hamidi, ${ }^{34}$ Hadian et al, ${ }^{36}$ Karami-Matin et $a l,{ }^{37}$ and Rezaei et al. ${ }^{38}$ The present payment system and induced demand has led to the fact that the wage of physicians is responsible for a majority of the human resources cost in the Iranian health sector. ${ }^{40,41}$ The share of physician payment to the healthcare costs has increased recently due to the government-led health system reform, according to which healthcare tariffs have grown by over $250 \%$, the burden of which being transferred largely to the insurance sector of SSO. ${ }^{42}$ On the other hands, MRTS revealed that for the same level of patient admission each unite of physician could be substituted by 1.8 unit of nurse. Given the significantly lower wage of nurses as compared with the doctors, the SSO, thus, can reduce this burden by employing nurses in medical procedures they can perform instead of physicians.

Based on our data, an increase of $10 \%$ in nursing input would enhance the hospital admissions rate by nearly $0.29 \%$, which is congruent with the previous studies employed the same methodology. ${ }^{33-38}$

The bed restoration interval is an indicator of effective use of beds. Our results showed that $10 \%$ increase in the restoration interval will reduce hospital admission by nearly $2 \%$. In the structure of the Iran's health system economy most revenue of hospital admissions is achieved by within 72 hours after admission. ${ }^{43}$ This fact, together with limited capacity of public hospitals has led to the optimal ALS to be targeted at 3.5 days in Iran. ${ }^{17}$ While this value is incomparably lower than the corresponding value in OECD countries (8.1 days), there is little evidence to show that factors contributing to quality of health care were considered in this targeting. The reported ALS in the direct healthcare services of the SSO is even lower (2.7 days) suggesting the unsatisfactory status of health care quality. At the same time, the negative contribution of bed restoration interval (BRI) to production points to the economic challenges associated with improving quality by targeting higher ALS.

Input coefficients for paraclinical staff and other staff were insignificant. While these two inputs were also reported to be insignificant in relevant studies conducted by Ghaderi et $\mathrm{al}^{35}$ and Mehraban, ${ }^{24}$ Jensen and Morrisey, ${ }^{33}$ Hadian et al, ${ }^{36}$ Karami-Matin et al, $^{37}$ Rezaei et al ${ }^{38}$ found positive significant effect for them. Nonetheless, the minus coefficient of paracinical staff indicates that the number of patient admissions reduces with the increase in paraclinical personnel. This can be explained by the notion that complete pre-admission checkup of patients in paraclinical/outpatient department may help to reduce nonemergency inpatient admissions. Inversely, the insignificant yet positive coefficient personnel's input is in line with the positive impact of adequate hospital staffing for admission, discharge, accounting, and other processes on hospital admission capacity.

\section{Conclusions}

Our results showed that health care services production in SSO is capital-intensive and highly dependent on active beds. The share of inefficiency component in the production process was found to be higher than that of random components, indicating the possibility of enhancing performance despite the very low rate of technical efficiency increase. The MRTS between physicians and nurses indicated that the growing burden of physicians' wage can 
be alleviated by employing nurses in the services they can deliver instead of physicians. Bed restoration interval showed significant negative contribution to production, pointing towards the challenges associated with improving quality by increasing ALS. The problem of inconsistency between quality services and high production, thus, persist indicating the need for in-depth reform in the structure of health care delivery.

\section{Abbreviations}

(SSO): social security organization; (SFA): stochastic frontier analysis; (MRTS): Marginal rate of technical substitution, (BOR): bed occupancy rate; (ALS): average length of stay; (BRI): bed restoration interval.

\section{Competing Interests}

There authors declare no competing interests.

\section{Authors' Contributions}

SM and HR jointly designed the study and determined the settings. SM collected the data and took part in data analysis. SM and HR contributed to data analysis and interpretation of the results. SM prepared the draft manuscript. All authors read and approved the final manuscript.

\section{References}

1. Roberts M, Hsiao W, Berman P, Reich M. Getting Health Reform Right: A Guide to Improving Performance and Equity. Oxford university press; 2003.

2. World Health Organization (WHO). World Health Organization (WHO) global health expenditure database. http://apps.who.int/nha/database/Home/Index/en.

3. Newbrander W, Barnum H, Kutzin J. Hospital economics and financing in developing countries. Geneva: WHO; 1992.

4. Blank JL, Valdmanis VG, editors. Evaluating hospital policy and performance: Contributions from hospital policy and productivity research. Jai Press; 2008.

5. Mills A. The economics of hospitals in developing countries. Part I: expenditure patterns. Health Policy Plan.1990;5(2):107-117.

6. Barnum H, Kutzin J. Public hospitals in developing countries: resource use, cost, financing. Johns Hopkins University Press; 1993.

7. Bloom G, Segall M, Thube C. Expenditure and financing of the health sector in Kenya: abridged report of a study performed for the Ministry of Health and the World Bank. Commissioned Study-Institute of Development Studies, University of Sussex (United Kingdom). 1993.

8. Sadaghyani E. A comparative study of hospital management methods in developed countries and Iran, National Report,
Islamic Parliament Research Center, 2003, report number 6648.

9. Tabibi M, Davodi A. An economic analysis of National Health Accounts in Iran during 2003-2012. Econ J. 2015;15(5):4164.

10. Sepehrdoust H, Rajabi E. Factors effective on technical efficiency and ranking of efficient units in social security hospitals. Director General. 2013;9(6).

11. Statistical Yearbook of the Social Security Organization of Iran, 2008-2015.

12. Rahimi B, Yusefzade H, Khalesi N, . Analysis of the efficiency and optimal consumption of resources in selected hospitals in Urmia province through data envelopment analysis (Persian). Journal of Health Administration. 2012;15(47):91102.

13. OECD. OECD Health Statistics 2015. Paris: OECD Publishing, 2015. doi:10.1787/health-data-en.

14. Younsi M. Performance of Tunisian public hospitals: a comparative assessment using the Pabón Lasso Model. Int J Hosp Res. 2014;3(4):159-166.

15. Kanwar V, Gupta AK, Goel S, Gupta PK. Hospital bed utilization: perceptions of healthcare practitioners from Northern India. Int J Hosp Res. 2015;4(3):113-138.

16. Aeenparast $A$, Farzadi $F$, Maftoon $F$, Zandian $H$, Rezaei Yazdeli M. Quality of hospital bed performance studies based on Pabon Lasso Model. Int J Hosp Res. 2015;4(3):143-148.

17. Jonaidi Jafari N, Sadeghi MO, Izadi MO, Ranjbar RE. Comparison of performance indicators in one of hospitals of Tehran with national standards. J Mil Med. 2011;12(4):223228.

18. Magnussen J. Efficiency measurement and the operationalization of hospital production. Health Serv Res. 1996;31(1):21-37.

19. Rezapour A, Arabloo J, Soleimani MJ, Ebadi Fard Azar F, Safari H. Microeconomic Analysis of Healthcare Services in Bou Ali Sina University Hospital. Int J Hosp Res. 2012;1(1):51-40.

20. Hatam N, Pourmohammadi K, Bastani $P$, Javanbakht M. Using parametric methods in hospital efficiency measurement: a case study in hospitals affiliated to social security and welfare ministry. Razi J Med Sci. 2013;20(110):29-36.

21. Hatam N. The role of data envelopment analysis (DEA) pattern in the efficiency of social security hospitals in Iran. Iran Red Crescent Med J. 2008(3):211-217.

22. Hajialiafzali H, Moss JR, Mahmood MA. Efficiency measurement for hospitals owned by the Iranian social security organisation. J Med Syst. 2007;31(3):166-172.

23. Sepehrdust H, Rajabi E. Technical efficiency measurement of social security hospitals. Journal of School of Public Health and Institute of Public Health Research. 2013;10(3):91-99. 
24. Mehraban S, Efficiency estimation in Iran's social security hospitals by data envelopment analysis, stochastic frontier analysis and utility-frontier production function methods. Deputy Economy and Planning, Social Security Organization of IRAN; 2012.

25. Aigner D, Lovell CK, Schmidt P. Formulation and estimation of stochastic frontier production function models. J Econom. 1977;6(1):21-37. doi:10.1016/0304-4076(77)90052-5.

26. Battese GE, Corra GS. Estimation of a production frontier model: with application to the pastoral zone of Eastern Australia. Aust J Agric Econ. 1977;21(3):169-179.

27. Meeusen W, Van den Broeck J. Efficiency estimation from Cobb-Douglas production functions with composed error. Int Econ Rev. 1977;18(2):435-444.

28. Greene W. Alternative panel data estimators for stochastic frontier models [Unpublished manuscript]. New York: Department of Economics, New York University; 2002.

29. Greene W. Reconsidering heterogeneity in panel data estimators of the stochastic frontier model. $\mathrm{J}$ Econom. 2005;126(2):269-303. doi:10.1016/j.jeconom.2004.05.003.

30. Jacobs R, Smith PC, Street A. Measuring Efficiency in Health Care: Analytic Techniques and Health Policy. Cambridge: Cambridge University Press; 2006.

31. Nouraei Motlagh S, Lotfi F, Hadian M, Safari H, Rezapour A. Factors influencing pharmaceutical demand in Iran: results from a regression study. Int J Hosp Res. 2014; 3(2):93-96.

32. Namara R, Upadhyay B, Nagar RK. Adoption and impacts of microirrigation technologies: empirical results from selected localities of Maharashtra and Gujarat States of India. International Water Management Institute; 2005.

33. Jensen GA, Morrisey MA. Medical staff specialty mix and hospital production. J Health Econ. 1986;5(3):253-276.

34. Hamidi S. Measuring efficiency of governmental hospitals in Palestine using stochastic frontier analysis. Cost Eff Resour Alloc. 2016;14:3. doi:10.1186/s12962-016-0052-5.

35. Ghaderi HO, Goudarzi G, Gohari MR. Determination technical efficiency of hospitals affiliated with Iran University of Medical Science by Data Envelopment Analysis
(2000-2004) (Persian). Journal of Health Administration. 2007;9(26):39-44.

36. Hadian M, Gohari MR, Yousefi M. The estimation of production function in Orumieh Medical Sciences University hospitals (Persian). Journal of Health Administration. 2007;10(29):7-14.

37. Matin BK, Soofi M, Falahi S, Karyani AK, Rezaei S. The estimation of production function among public hospitals of Kermanshah University of Medical Sciences (2001-11) (Persian). J Kermanshah Univ Med Sci. 2013;17(5):325-331.

38. Rezaei S, Miraki T, Jahanmehr N, Gharibi F. The estimation of production function in educational hospitals of Kurdistan University of Medical Sciences (2007-2011). Journal of Hospital. 2014;13(1):9-16.

39. Hatam N, Pourmohammadi K, Bastani P, Javanbakht M. The survey of hospital size effect on technical efficiency in social security hospitals. Razi J Med Sci. 2013;20(108):61-69.

40. Babashahy S, Baghbanian A, Manavi S, Sari AA, Manesh AO, Ronasiyan R. Towards reforming health provider payment methods: evidence from Iran. Health Scope. 2016. doi:10.17795/jhealthscope-33575

41. Babashahy S, Baghbanian A, Manavi S, et al. Insight into Provider Payment Mechanisms in Healthcare Industry: A Case of Iran. Iran J Public Health. 2016,45(5):693.

42. Moradi-Lakeh M, Vosoogh-Moghaddam A. Health sector evolution plan in Iran; equity and sustainability concerns. Int J Health Policy Manag 2015;4(10):637-640. doi:10.15171/ ijhpm.2015.160.

43. Asefzadeh S. Principles of health Economics (Persian). Qazvin: Qazvin University of Medical Sciences; 2005:80-1.

\section{Please cite this article as:}

Mehraban S, Raghfar H. Estimation of production function of direct health care services delivered by Iranian social security organization. Int J Hosp Res. 2016;5(2):46-51. doi:10.15171/ ijhr.2016.09. 